\title{
Design and Application Research on Electrical Automation Control System Based on Computer Technology
}

\author{
Ming Liu ${ }^{1, \mathrm{a}^{*}}$ and Bo $\mathrm{Li}^{2, \mathrm{~b}}$ \\ ${ }^{1}$ School of Information Engineering, Zhengzhou University of Industrial Technology, \\ Zhengzhou Henan 451150,PR China \\ ${ }^{2}$ School of Information Engineering, Zhengzhou University of Industrial Technology, \\ Zhengzhou Henan 451150,PR China \\ a Immails@163.com, ${ }^{\text {b } 357696640 @ q q . c o m ~}$
}

Keywords: Computer technology; Electrical automation; Control system

\begin{abstract}
With the continuous innovation and development of computer technology, the electrical automation control system, based on computer technology, has been widely applied in various manufacturing life, so that the industrialization level of the economic society is greatly improved. The design and application of electrical automation control system have more and more important social value and significance. In this paper, the characteristics of information management of computer are studied in depth, and the design of electrical automation control system based on computer technology is analyzed in detail. Finally, the application of electric automation control system based on computer technology was further explored to provide Suggestions with reference value for the design of electrical automation control system based on computer technology and the lifting of application effect.
\end{abstract}

\section{Introduction}

With the development of science and technology, the application of various electric equipment is becoming more and more prevalent, and the application of electrical automation is also becoming widespread. Electrical automation control system is an integrated control management system based on computer technology and electronic communication technology, capable of realizing intelligent and efficient operation. Application of electrical automation control system in industrial production, in addition to being able to realize the protection of electrical control and monitoring, can also be produced by fault in the electrical control problems of automatic alarm. [1] It can also scientifically guarantee the operation safety of the power distribution system, accurately measure the power, effectively control the power consumption, and truly realize energy saving and facilitate people's production and life.

\section{Computer Technology and Information Management}

Advantages of computer information management. The management of data information through computer technology is mainly because the computer has the following advantages: First of all, the emergence of computer and the development of computer technology have greatly satisfied people's needs and accelerated the efficiency of people's work and life. Secondly, the computing power of the computer can help people to deal with complicated information, which greatly liberates the labor force and reduces the cost. The computer technology is well suited to the needs of different industries, not only to be able to design special application systems, but also to ensure the reliability and safety of information data transmission and storage, and reduce the risk of leakage of information data.[2]

Computer and engineering projects. In general engineering projects, the management of information data is a vital part of it. When the project started, the design, planning, operation and maintenance began. Project management involves a lot of large scale work, which brings huge amount of information and data, so the importance of information management becomes apparent. 
In the actual project management, it will be found that the increase of data information brings great difficulties to data collection and collation and classification analysis. The engineering project is full of variables, and managers must keep abreast of the latest project progress, so they must build a database to manage the project through computer technology. The emergence of computer technology has led to the possibility of dynamic management. Through computer technology, data information can be stored, analyzed and processed in real time.[3]The manager can get the information he needs quickly and intuitively through the computer. It not only improves the work efficiency, but also reduces the economic cost and saves a lot of human resources.

\section{System Design and Analysis.}

Electrical load automation. The main reason for the design of electrical load automation system is to ensure the stable and safe operation of the power grid. It is responsible for the effective supervision and management measures for the operation of electric basic load. Today, with the rapid development of industry, the traditional monitoring mode of electrical load management has been unable to meet the increasing demand of power. Therefore, it is necessary to continuously update the direction of electrical automation control, and gradually abandon the traditional power load management mode in the continuous updating. [4]The electrical automation control system will gradually emerge as an important role in the development of future control systems. With the development of science and economy, most electric departments have the right electrical automation control system. Through the load system used in electrical automation control system, realized the supervision, control, and automatic inspection, speeds up the possibility of various information resources sharing in the power system.

Electrical automation communication system. Communication system is an important part of the electrical automation control system, which is directly related to the accuracy of data and the timeliness of transmission. There are two main methods of communication, namely, wired communication and wireless communication.

The wired communication itself has the advantages of convenient connection and low input cost, but it also has some defects. For example, the reliability and security in the communication process are poor, which may not be timely and effectively communicated, and the timeliness cannot be guaranteed. As a result, wired communication is mainly used in the distribution terminal with low real-time requirement.

Wireless communication is mainly achieved through radio equipment communication and high-speed intelligent transmission. In general, radio communication is mainly used for the supervision and operation of electrical load. Compared with the previous cable communication, the input cost is low, but its own reliability is weaker than that of wired communication. Therefore, radio equipment communication is mainly used in distribution terminals with low reliability requirements. High-speed intelligent transmission is much more advantageous than radio communication. Its advantages are mainly reflected in the high accuracy of transmission content, fast transmission speed, and the ability to choose routes at will. The power grid operation state can be automatically reported in real time, with extremely high reliability and security. However, the corresponding input capital is obviously higher than other communication methods. The high-speed intelligent communication method is mainly used in the distribution terminals with higher reliability requirements. [5]

Fieldbus Control System. Fieldbus control system mainly adopts the method of bidirectional data transmission of information, by the point and the surface, a one-to-many method, high accuracy on the information data content, in use process can also be used in the inspection of electrical equipment running status is abnormal, and timely report. Although the information data is accurate, but the transmission rate is relatively slow, there is no way to connect the large number of electrical equipment at the same time. The information transfer protocol between the devices cannot be unified, and the system is not compatible with the intelligent instrument, and cannot be connected directly. The system must be corresponding to other auxiliary equipment and auxiliary functions to ensure the normal and stable operation of the system. 
Distributed control design. The CPU is the core part of the electrical automation control system. The effective information provided by intelligent instruments such as circuit breakers and inverters is gathered at the central processing unit, and the specific useful information is selected through the unified processing of the central processing unit. The distributed control system is designed to help the central processor to analyze and analyze the information data, to form an effective branch framework, and to connect the CPU with other different kinds of intelligent facilities through the classification of different data, which can directly and effectively improve the intelligent control efficiency of the pass-through.[6]

Centralized monitoring design. The centralized monitoring principle of the electrical automation control system is to centralize the information data of the electrical automation control system to the same central processing unit. Because of the huge amount of information collected and processed, the speed of the system is bound to slow down. When the electrical automation system in detecting control running status, involves more operations, which resulted in increased cable quantity increased, the host space occupied, causing signal transmission distance, affecting transmission efficiency. [7]Therefore, in the design of the centralized monitoring of the electrical automation control system, it is necessary to comprehensively consider the safety, accuracy and convenience of centralized monitoring.

Remote monitoring design. The electrical automation control system is characterized by high security, high reliability and high flexibility. Remote monitoring of the electrical automation system will not only save the cost, save the cable installation, but also reduce the power of the cable, reduce the amount of cable maintenance. However, when remote monitoring is carried out by the electrical automation control system, it is difficult to establish an electrical automatic control system for the whole process management due to the monitoring of large-scale systems, so that the communication speed of remote monitoring cannot meet the actual demand. Therefore, it is necessary to take effective measures to improve the communication speed of remote monitoring and improve the operation safety of the electrical automation control system.

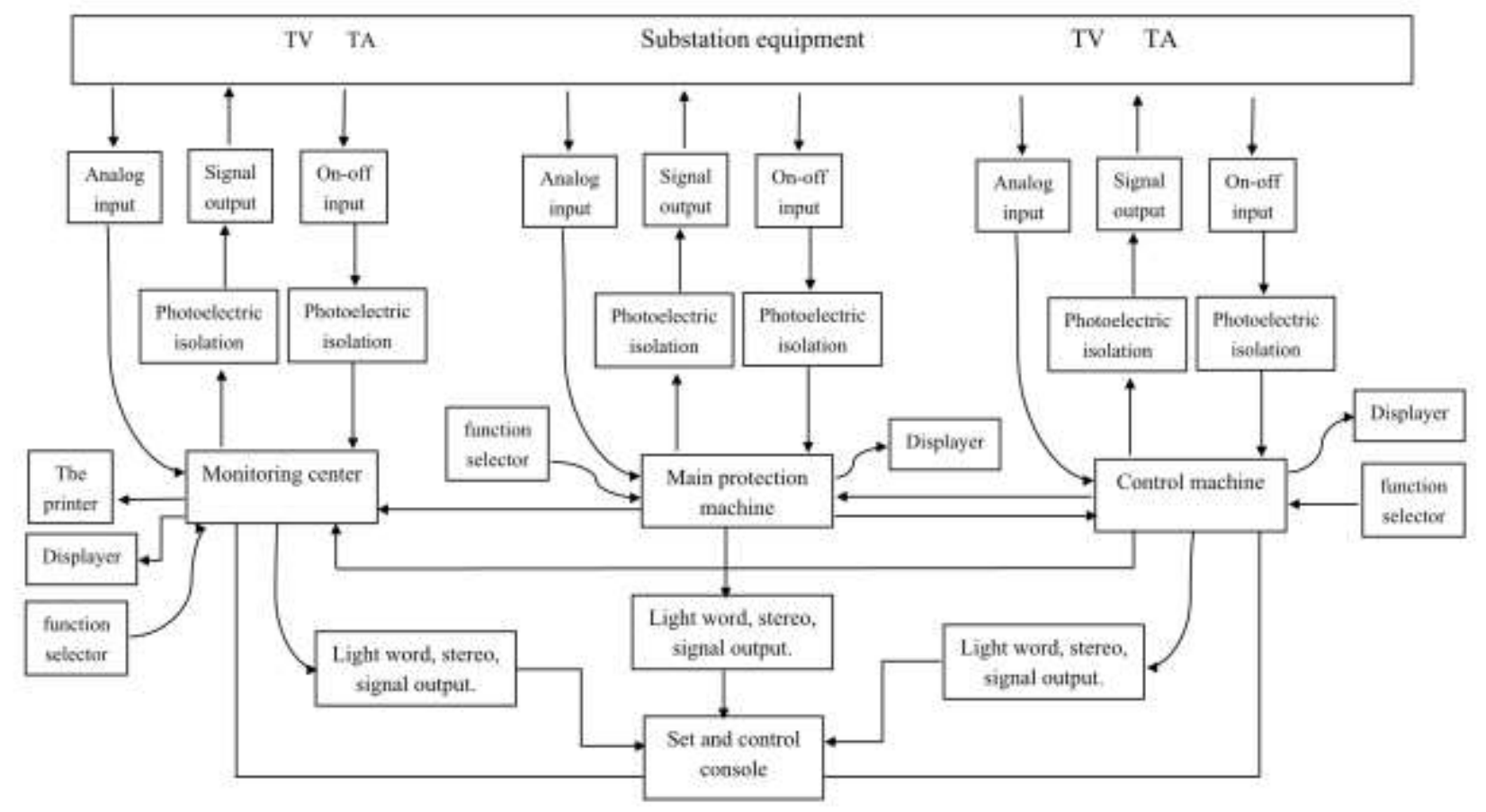

Figure 1. Substation microcomputer monitoring and protection integrated control system block diagram

\section{The Application of Electrical Automation Control System based on Computer Technology}

Data acquisition and computer processing system. Computer processing system refers to the 
basic processing system based on computer, which consists of input, processing and output. The application of automatic control system to power plant power generation system is mainly to collect data information contents, input system parameters, display system parameters, and timely alarm and record the sequence of accidents in case of abnormal operation. By analyzing the data comprehensively and implementing specific operation, the computer can control some operating system quickly and effectively, so as to ensure the smooth and efficient operation of the whole power grid, so as to make real-time monitoring of the operation condition of the power grid.

Electric hydraulic regulating system of steam turbine. The traditional steam turbine control mainly adopts hydraulic control system. With the development of The Times and the continuous innovation of science and technology, the performance of electrical facilities and components is getting better and better. The electro-hydraulic regulation system gradually replaces the traditional hydraulic control system and becomes the most widely used control system. The system is mainly designed to ensure the smooth operation of the power grid and to ensure that the load can be effectively changed, which is effective for improving the operation of the electric unit, and the safe and reliable operation of the unit can be greatly reduced.[8]

Instrument monitoring system. With the increasing capacity of the generator set, the corresponding number of instruments also increases. This is because the turbine needs to use a large number of instruments to monitor and manage various parameters to prevent the occurrence of safety accidents. Applied in the steam turbine generator unit of electrical automation control system based on computer technology can be systematic records of these parameters. It can not only monitor the chain protection system of electrical units, but also improve the security and reliability of the system.

The development of substation automation technology. In the 1980s, due to the development of microcomputer technology, remote terminal RTU, local monitoring and other devices were upgraded, and a microcomputer-based substation automation system based on RTU was established. This system not only involves relay protection, but also retains the original traditional control platform. In the 1990s, microcomputer protection technology was widely used. At this time, the substation automation system was installed in the substation control room to set up the computer system as the heart of substation automation, and a data collection and control unit was set up to collect data and issue control commands.[9] With the development of computer hardware and software and network technology, the general substation automation system has realized decentralized distributed structure, and the whole system is divided into substation layer and interval layer. The substation layer includes integrated operation screen, application host, software development and management engineer host, whole station monitoring, communication, remote host; The interval layer is usually divided according to circuit breaker interval, and each interval layer device realizes the function of a circuit breaker. At present, many manufacturers in China and abroad have developed the automatic control system of substation based on CAN and LonWorks bus, and achieved good results.

Future development. With the innovation and development of computing technology, the electrical industry has been revolutionised again and again. The upgrading and improvement of electric facilities is driving the reform of the electric industry. As the new equipment continues to appear, the control system must be adjusted and improved in order to better adapt. Traditional control system is gradually replaced by more diversified and convenient automatic control system because of its uniqueness and limitation, which is in line with the development of modern society. The future automation control system will not be limited to the management of electrical facilities, but will expand to more and broader aspects to ensure the smooth development of the work.

\section{Conclusion}

Because of electrical automation technology covers many fields such as agriculture, industry, national defense, so it is directly related to the social and economic development.

The electrical automation control system completely changes the management mode of the conventional substation, which can not only ensure the safe and reliable distribution of the power 
distribution, but also reduce the occurrence of power failure as much as possible. The electrical automation control system based on computer technology can combine automation technology and computer technology, and provide high quality electric power service for power department, which can save energy resources greatly.

Therefore, we need to continue to study the design and application of electrical automation control system, so that the technology can be further improved and developed.

\section{References}

[1] Tang jing. Discussion on the application and development of electric automation control system [J] .electronic world.2014 (3) : 87.

[2] Liu ying, Zhong yuzhen. Application and development trend of electric automation control system [J]. Electronic test, 2013 (7) : 45-46.

[3] Zhou chao. Integration analysis of computer application technology and information management [J]. Information communication.2015 (10):151-152.

[4] Zhao yuhong. Design and application of electrical automation control system [J] .China equipment engineering.2017 (07) : 156-157.

[5] Tang yifan. Design exploration of electrical automation control system under the application of computer technology [J]. Electronic test.2014, (10):96-98.

[6] Lu haibo. Design of electrical automation control system [J]. Automation control, 2015 (02) : 170-171.

[7] Han peng. Design and analysis of electrical automation control system based on computer technology [J]. Electronic technology and software engineering, 2015:142-143.

[8] Ma lan. Integrated analysis of computer application technology and information management [J]. Information communication.2015 (10) :151-152.

[9] Liu yan. Design and analysis of electrical automation control system based on computer technology [J]. Power message, 2017 (7) :174-175. 